\title{
Adherence to Antiretroviral Therapy for the Success of Emerging Interventions to Prevent HIV Transmission: A Wake up Call
}

\author{
Jean B Nachega ${ }^{1,2, *}$, Olalekan A Uthman ${ }^{3}$, Edward J Mills ${ }^{4}$, and Thomas C Quinn ${ }^{5,6}$ \\ ${ }^{1}$ Johns Hopkins University, Departments of International Health and Epidemiology, Baltimore, MD, USA \\ ${ }^{2}$ Stellenbosch University, Department of Medicine and Centre for Infectious Diseases, Cape Town, South Africa \\ ${ }^{3}$ Stellenbosch University, Center for Evidence-Based Health Care, Cape Town, South Africa \\ ${ }^{4}$ University of Ottawa, Department of Global Health, Ontario, Canada \\ ${ }^{5}$ Johns Hopkins University, Center for Global Health, Baltimore, MD, USA \\ ${ }^{6}$ Division of Intramural Research, National Institute of Allergy and Infectious Diseases, National Institutes of Health, Bethesda, MD, USA
}

\begin{abstract}
Despite recent successes in several HIV prevention trials, the epidemic continues to increase in many countries. The most successful biomedical interventions to prevent HIV have been the use of Antiretroviral Therapy (ART) to Prevent Mother-To-Child Transmission (PMTCT), and sexual transmission via microbicides, PreExposure Prophylaxis (PrEP), and treatment of the infected person within discordant couples. In addition medical male circumcision has also been shown to be highly effective in prevention of HIV acquisition. However, emerging data demonstrate that adherence to several of these prevention interventions is critical. ART adherence during and after pregnancy has been shown to be significantly below that recommended for adequate virologic suppression, particularly during the postpartum period. Five recent PrEP trials also demonstrate that the success of PrEP as a public health intervention will necessitate monitoring ART adherence and will include additional interventions to improve or maintain adherence to optimal levels. New successes in HIV prevention research have been tempered by suboptimal adherence. There is a critical need to define practical and effective adherence monitoring strategies as well as controlled trials of adherence interventions in the era of PrEP, Treatment as Prevention (TasP), and PMTCT to maximize their benefit.
\end{abstract}

Keywords: Adherence; PMTCT; ART; PreP; TasP

\section{Introduction}

According to WHO/UNAIDS, there are currently 34 million people living with human immunodeficiency virus (HIV), and in 2011, 2.7 million people became newly infected despite recent successes in HIV prevention. The epidemic continues to increase in many countries, calling for more aggressive and integrated HIV/AIDS prevention programs in order to prevent new infections and slow the progression of this pandemic [1,2]. Thirty years into the HIV epidemic, research has demonstrated that we have effective interventions to prevent new infections through condom use [3-6], safe injecting [7], medical male circumcision [8-10] and use of Antiretroviral Therapy (ART) as prevention [11-13]. For the first time, there is international discussion that we can stop HIV transmission on a large scale with these new interventions. However, emerging data are also showing that adherence to several of these prevention interventions is critical. Indeed, interventions to promote adherence to behavior changes and treatment are necessary to decrease transmission. This is not a surprising finding, but rather a wake-up call, since it has been shown that ART adherence is among the strongest predictors of virological $[14,15]$ and immunological [16] success and ultimately survival [17,18].

In this narrative review, we give an overview of the past, present and future of HIV prevention research, and in doing so we highlight the important role of adherence, the available evidence-based interventions to address non-adherence, and the need for future research.

\section{HIV Prevention Research: Failures, Successes and Chal- lenges}

The year 2011 marked the 30th anniversary of the first reported cases of what is now known as AIDS, a disease that has claimed the lives of at least 30 million people worldwide. 2010-11 saw major developments in HIV prevention research resulting in optimism about interventions including vaginal gels, pre-exposure prophylaxis with antiretrovirals and treatment of infected partners as a form of prevention. This is in stark contrast to the 1980s and 90s, where the major focus of prevention efforts was mostly on behavioral change to decrease risky sexual behaviour, promotion of condoms as well as harm reduction with safe injecting programs. Recently, the results of multiple randomized double-blind controlled trials evaluating biomedical interventions to decrease transmission of HIV have been reported. Treatment of Sexually Transmitted Infections (STIs), has had mixed results, depending in part on the timing of the epidemic and the frequency of the STIs in the populations [19-21]. Several proofof-concept trials focusing on treatment of HSV-2 to prevent HIV transmission and acquisition, while initially appeared promising, a larger phase- 3 trials failed to show an effect [22]. Another subsequent failure was the inability to identify a protective microbicide despite numerous trials, several of which increased HIV incidence [23-25]. Furthermore, female barrier contraceptives such as a diaphragm were also ineffective [26]. Finally, intensive research efforts for more than two decades have not yet resulted in a safe and efficacious HIV vaccine $[27,28]$.

*Corresponding author: Jean B Nachega, Johns Hopkins University, Departmen of International Health, Global Disease Epidemiology Program, $615 \mathrm{~N}$ Wolfe Street, W5031, Baltimore, Maryland 21205, USA, Tel: +410 955 2378; Fax: +1 410502 6733; E-mail: jnachega@jhsph.edu

Received June 12, 2012; Accepted October 18, 2012; Published October 22 2012

Citation: Nachega JB, Uthman OA, Mills EJ, Quinn TC (2012) Adherence to Antiretroviral Therapy for the Success of Emerging Interventions to Prevent HIV Transmission: A Wake up Call. J AIDS Clinic Res S4:007. doi:10.4172/2155-6113.S4007

Copyright: (c) 2012 Nachega JB, et al. This is an open-access article distributed under the terms of the Creative Commons Attribution License, which permits unrestricted use, distribution, and reproduction in any medium, provided the original author and source are credited. 
During the last four years, the use of Antiretroviral Therapy (ART) to prevent HIV has changed the landscape of HIV control. The most successful intervention to prevent HIV has been the use of ART to prevent Mother-To-Child Transmission (MTCT), prevention of sexual transmission via microbicides, preexposure prophylaxis, treatment of the infected person within discordant couples, and medical male circumcision.

\section{ART Adherence and Prevention of Mother to Child Transmission of HIV}

Numerous studies have shown that reduction of viral load with ART during pregnancy and breast feeding reduces MTCT. In ideal conditions, provision of ART and replacement feeding or continued ART with breastfeeding can reduce transmission from an estimated 30$35 \%$ with no intervention to $1-2 \%$ in both developed and developing countries $[29,30]$. PMTCT has arguably been the greatest success in HIV prevention and there remains an urgent need to scale-up MTCT prevention in order to reach those who are at greatest risk [29]. ART use by pregnant and lactating HIV-infected women is critical for both preserving maternal health as well as prevention of MTCT. There is good evidence that longer and more complex antiretroviral regimens are associated with the lowest rates of perinatal transmission. Furthermore, recent studies have shown that giving antiretroviral drugs to the mother or infant during breastfeeding significantly reduces postnatal transmission. In addition, given evolving data on the benefits of earlier treatment for HIV-infected individuals in general, both for their own health and to prevent transmission to uninfected sexual partners, there is an increasing move in low-resource settings towards the use of triple drugs during pregnancy and breastfeeding, both for mothers who require treatment as well as those who do not yet require treatment, and some countries are implementing a program where HIV-infected pregnant women are initiated on life-long treatment (WHO option $\mathrm{B}+$ ).

Optimal adherence remains a challenge in pregnancy, in both highand lower-income countries, and particularly during the postpartum period [14]. In a recent meta-analysis by Nachega and colleagues ART adherence during pregnancy was significantly below that recommended for adequate virologic suppression, as demonstrated in 51 studies involving 20,153 HIV-infected pregnant women. Most studies were from United States $(n=14,27 \%)$ followed by Kenya $(n=6,12 \%)$, South Africa $(n=5,10 \%)$, and Zambia $(n=5,10 \%)$. The threshold defining good adherence to ART varied across studies $(>80 \%,>90 \%,>95 \%$, $100 \%)$. A pooled analysis of all studies indicated that a pooled estimate of $73.5 \%$ (95\% Confidence Interval [CI] 69.3-77.5\%). of pregnant women had adequate $(\geq 80 \%)$ ART adherence. The pooled proportion of women with adequate adherence levels was higher during the antepartum $(75.7 \%, 95 \%$ CI $71.5-79.7 \%)$ than during the postpartum period $(53.0 \%, 95 \% 32.8 \%$ to $72.7 \%)(\mathrm{p}=0.005)$ [14]. These data are problematic and alarming for low-resource settings where breastfeeding occurs, and where use of maternal triple antiretroviral drug regimens during breastfeeding is a recommended option for prevention of postnatal transmission. These data also call for investigations of specific risk factors for ART non-adherence in ante- and post-partum and interventions to address them globally.

\section{ART Adherence in Pre-Exposure Prophylaxis Trials}

During the last two years, the scientific community documented the efficacy of ART to prevent sexual transmission. The quantity of HIV in plasma and genital secretions is the prime determinant of HIV transmission risk and initiation of ART in HIV-infected individual's results in early and sustained reductions in plasma and genital HIV levels [31]. Therefore, it was hypothesized that treating HIV-infected individuals with antiretroviral medications reduces their infectiousness and risk of transmission to partners.

In Pre-Exposure Prophylaxis (PrEP), an HIV-uninfected individual uses an antiretroviral medication prior to an HIV exposure. By having therapeutic levels of the antiretroviral medication already in their blood and tissues, PrEP may prevent HIV from establishing infection, analogous to prophylaxis for malaria in travelers. There are several published observational studies documenting the use of ART in preventing transmission of HIV in discordant couples [32]. Tenofovirbased PrEP use either with tenofovir (TDF) alone or in combination with emtricitabine (TDF/FTC) sold under the trade name Truvada is a daily oral pill with broad and potent activity against all HIV subtypes with favorable safety and tolerability.

To date, five important PrEP trials have been completed. The first two trials included the Centre for the AIDS Program of Research in South Africa 004 trial (CAPRISA004), which tested pericoitally applied $1 \%$ tenofovir (TDF) vaginal gel among 889 South African young sexual active women [33], and the PreExposure Prophylaxis Initiative (iPrEx) trial, which evaluated daily oral TDF/FTC among 2,499 men who have sex with men and transgender women from six countries (US, Brazil, Ecuador, Peru, South Africa, and Thailand) [34]. In CAPRISA 004, TDF gel reduced HIV acquisition risk by $39 \%$ (95\% Confidence Interval [CI]: 6-60\%; $\mathrm{P}=0.017)$. In iPrEx, oral TDF/FTC reduced HIV risk by $44 \%(95 \% \mathrm{CI}, 15-63 \% ; \mathrm{P}=0.005)$. In both trials, protection against HIV was substantially higher among those with high ART adherence: 54\% efficacy in CAPRISA 004 among participants with $>80 \%$ adherence and $73 \%$ efficacy in iPrEx for participants with $>90 \%$ adherence. These results clearly demonstrate that the success of PrEP as a public health intervention will necessitate monitoring ART adherence and interventions to improve or maintain adherence to optimal levels.

Five months after the announcement of iPrEx's promising results, a large trial of oral preexposure prophylaxis in women 18-35 years of age in South Africa, Kenya, and Tanzania called FEM-PrEP was closed in April 2011 due to futility [35]. At the time the study was stopped, 2120 HIV-uninfected African women were enrolled, with 68 incident infections, 33 in the TDF/FTC arm and 35 among placebo recipients. Use of TDF/FTC was associated with increased gastro-intestinal side effects but not increased creatinine levels. Poor adherence seemed the likely explanation for non-efficacy since patient self-reported adherence (around 95\%) and pill count (around >85\%) were discrepant with drug levels assessed in a subset of patients, showing that detectable TDF levels were seen only in $<40 \%$ of those tested, and $<30 \%$ among those randomized to active drug. It was clear that with this low level of adherence, it would have been impossible for this study to demonstrate any efficacy of TDF/FTC for HIV prevention in this study population. At the same time, the data underscored the importance of adherence as well as the difficulty in making accurate assessments of therapy-taking behaviour. In late 2011, the assessment of oral and vaginal tenofovir in the Microbicide Trial Network (MTN)-003 trial called VOICE (Vaginal and Oral Interventions to Control the Epidemic) was stopped for futility [36] in Uganda, Zimbabwe and South Africa but the TDF/FTC versus placebo arm are still ongoing (Table 1) and results are expected in 2013. Final results about why oral and vaginal tenofovir did not show efficacy in VOICE are not known fully understood yet, but it is likely that low adherence played a crucial role as well.

The results of two other PrEP trials were announced in July 2011 at the international AIDS Society Conference in Rome. Both showed efficacy higher than the iPrEx trial. The TDF2 study compared TDF/ 
FTC against placebo in 1,200 heterosexual men and women (600 per arm) in Francistown, Botswana, one of the world's highest-prevalence locations for HIV. In the primary analysis, there were nine HIV infections among the 601 participants who received TDF/FTC and 24 among the 599 who received placebo, translating into a statistically significant $62.6 \%$ (95\% CI $20.3 \%$ to $82.5 \%$ ) reduction in infections. Of note, a secondary analysis excluding infections that occurred among participants who had run out of their pills and who had not taken one for at least 30 days showed $77.9 \%$ fewer infections in people taking TDF/FTC [37]. The Partners for PrEP Trial took place in Kenya and Uganda. It recruited 4758 couples, of whom 4747 were followed: 1584 randomly assigned to TDF, 1579 to TDF-FTC, and 1584 to placebo. For $62 \%$ of the couples followed, the HIV-1-seronegative partner was male. A total of $82 \mathrm{HIV}-1$ infections occurred in seronegative participants during the study, 17 in the TDF group, 13 in the TDF-FTC group, and 52 in the placebo group, a relative reduction of $67 \%$ in the incidence of HIV-1 with TDF (95\% CI: $44-81 ; \mathrm{P}<0.001)$ and of $75 \%$ with TDF-FTC (95\% CI, 55-87; $\mathrm{P}<0.001$ ). Of note, protective effects of TDF-FTC and TDF alone against HIV-1 were not significantly different $(\mathrm{P}=0.23)$ [38].

There is a clear relationship between PrEP adherence use and HIV protection in all five clinical trials. Divergent PrEP trial results appear to be correlated with PrEP adherence behaviors (Table 1). A clear premise is that PrEP cannot work if it is not taken and there is a clear dose-response between evidence of PrEP use and efficacy. When PrEP was taken as prescribed and detected in blood, protection was very high (Table 2). Of note, overall, relatively low adherence levels were observed in the iPrEx and FEM-PreP trials. Yet evidence of benefit was found in the former. This observation may suggest that Truvada is more forgiving of imperfect use for rectal rather than vaginal exposure to HIV, possibly due to differential concentration of the active drug in rectal compared to vaginal tissues $[34,35]$.

Risk perceptions seem to play a potential powerful driver of adherence in PrEP studies. Adherence counseling was offered to both partners in the Partners for PrEP trial, and overall, high levels of adherence was documented in this trial using intensive adherence monitoring and followed by an intervention for participants with less than $80 \%$ adherence [39]. Qualitative data by Ware and colleagues suggest that trust and commitment within the partnership were critical for supporting adherence in this study [40]. Known HIV+ partner, ongoing exposure, and a decision to maintain relationship, were all associated with high adherence. In FEM-PrEP which enrolled young women, about $70 \%$ perceived themselves to be at little or no HIV risk, and had documented very low adherence. In iPrEx, men who practiced unprotected receptive anal intercourse had higher PrEP use than other men, and received highter HIV protection (58\% in subgroup efficacy). Men not having sex were least likely to take PrEP. Of note, there was no evidence of risk compensation in these PrEP clinical trials. Understanding the interface of risk perception and HIV prevention is key for any strategy. Also, it is important to consider the temporal patterns of adherence and sexual exposure such as isolated lapses combined with high-risk sexual exposures can lead to transmission, while low adherence confers little risk in the absence of sexual exposure [41]. Finally, in addition to non-adherence, variable drug concentration at the exposure site, integrity of the vaginal epithelium, and the role of acute infection have been reported as potential explanations for divergent PrEP trial results to date [41].

\section{ART Adherence and Virologic Suppression in the HIV Prevention Trial Network (HPTN) 052 Trial}

Similar to PrEP, antiretroviral Treatment as Prevention (TasP) in HIV-infected individuals requires high adherence in order to achieve prevention benefits. Viral suppression is the biologic pathway to efficacy. The results from HPTN 052 trial are very clear in this regard - and were an optimized study of the biologic hypothesis that ART diminishes HIV infectiousness. In this trial, 10, 838 Hiv-infected individuals were screened and 1763 couples were enrolled. Fifty percent of the infected participants were men. Compared to deferred arm, the

\begin{tabular}{|c|c|c|c|c|c|}
\hline $\begin{array}{l}\text { Study } \\
\text { (Active Product) }\end{array}$ & Population & Sample Size & Country & $\begin{array}{l}\text { Overall Adherence Levels and Method of } \\
\text { Measurement }\end{array}$ & $\begin{array}{l}\text { Efficacy Results } \\
\text { Point Estimate; } 95 \% \text { Cls; } \\
\text { and P-Value }\end{array}$ \\
\hline $\begin{array}{l}\text { CAPRISA 004[33] } \\
\text { (Tenofovir } 1 \% \text { gel) }\end{array}$ & Heterosexual women & $N=889$ & South Africa & $\begin{array}{l}70 \% \text { by monthly count of product application } \\
\text { divided by number of reported sex acts }\end{array}$ & $39 \%(6-60) ; P=0.017$ \\
\hline $\begin{array}{l}\text { iPrEx [34] } \\
\text { (FTC/TDF) }\end{array}$ & $\begin{array}{l}\text { MSM and transgender women } \\
\text { who have sex with men }\end{array}$ & $N=2499$ & $\begin{array}{l}\text { Peru, Equator, South Africa, } \\
\text { Brazil, Thailand, USA }\end{array}$ & $\begin{array}{l}95 \% \text { by self-report; } 89-95 \% \text { by pill count; } \\
54 \% \text { by drug concentrations/PBMC }\end{array}$ & $44 \%(15-63) ; P=0.005$ \\
\hline $\begin{array}{l}\text { TDF2 Study[37] } \\
\text { (FTC/TDF) }\end{array}$ & Heterosexual men and women & $N=1200$ & Botswana & $84 \%$; Monthly pill count & $62 \%(20-82) ; P=0.026$ \\
\hline $\begin{array}{l}\text { Partners for PrEP[38] } \\
\text { (TDF or FTC/TDF) }\end{array}$ & Heterosexual couples & $N=4758$ & Uganda, Kenya & $\begin{array}{l}\text { 95\%; Monthly self-report, pill count and drug } \\
\text { concentrations }\end{array}$ & $\begin{array}{l}67 \%(29-85) ; P=0.01 \text { TDF } \\
\text { alone } \\
55 \%(4-79) ; P=0.001 \text { FTC/ } \\
\text { TDF }\end{array}$ \\
\hline FEM-PrEP[35] & Heterosexual women & $N=2120$ & $\begin{array}{l}\text { Kenya, South Africa, } \\
\text { Tanzania }\end{array}$ & $\begin{array}{l}95 \% \text { by self-report; } 85 \% \text { by pill count; } 40 \% \\
\text { and } 30 \% \text { by drug concentration in the overall } \\
\text { population and among those who received } \\
\text { the active drug, respectively }\end{array}$ & Stopped for futility \\
\hline $\begin{array}{l}\text { MTN-003[36] } \\
\text { (VOICE) }\end{array}$ & Heterosexual women & $N=5029$ & $\begin{array}{l}\text { Uganda, Zimbabwe, South } \\
\text { Africa }\end{array}$ & $\begin{array}{l}\text { Adherence levels by monthly self-report, pill } \\
\text { count and drug concentration not available }\end{array}$ & $\begin{array}{l}\text { Stopped for futility for TDF } \\
\text { and TDF gel; Ongoing for } \\
\text { FTC/TDF }\end{array}$ \\
\hline
\end{tabular}

Table 1: PrEP Trials Efficacy Results and Levels of Adherence.

\begin{tabular}{|l|c|c|}
\hline & Percentage of blood samples with tenofovir detected (\%) & HIV protection efficacy in randomized comparison (\%) \\
\hline Partners PrEP[38] FTC/TDF arm & 81 & 75 \\
\hline TDF2[37] & 79 & 62 \\
\hline iPrEx[34] & 51 & 44 \\
\hline FEM-PrEP[35] & 26 & 6 \\
\hline
\end{tabular}

Table 2: Adherence as Evaluated by Blood Concentrations and Efficacy in PrEP Trials. 
immediate initiation group had 1 transmission vs. 27 in the delayed arm $(\mathrm{p}<0.0001)$ with a relative risk $=0.037$, meaning $96 \%$ prevention efficacy. In this trial, high levels of ART adherence (at least 95\%) as measured by pill count was documented in $79 \%$ of participants in the early-therapy group and in $74 \%$ of those in the delayed-therapy group. All participants received intensive ART adherence counseling. HIVinfected study participants who received ART at a median of CD4 count of $446 / \mathrm{mm} 3$ had fewer clinical outcomes compared to those who delayed ART until their CD4 count was between 200 and 250/mm3 (mostly tuberculosis). In addition, viral suppression was near-universal, reflecting intensive strategies to achieve near-perfect adherence [11] To demonstrate that treatment can work at a population level to stop the spread of HIV, ecological studies and mathematical models have been convincingly employed $[12,13,42,43]$.

However, in the real-world, ART adherence is far perfect and contrast with perfect trial conditions of HPTN052. Indeed, Mills et al. showed in a meta-analysis involving 28,689 patients that only $55 \%$ (95\%CI: 48-61) of patients in North America versus 77\% (95\%CI: 6786) of HIV-infected adults in Africa had documented optimal ART adherence (>80\%) [44]. Also, reported data from CDC shows that of 1.1 million with HIV infection in the US, only 328,000 (28\%) have suppressed HIV RNA [45]. Therefore, there is need for ongoing ART adherence monitoring, and if needed, targeted adherence support interventions to maintain or improve optimal level of adherence in the context of TaSP and PrEP to prevent emergence of drug resistance, virologic failure and disease progression.

\section{Monitoring of ART Adherence Monitoring and Possible Interventions and Research Agenda}

To date there are no established gold standard methods to measure adherence since each tool has its own limitations. Participant's selfreport has limited accuracy and tends to overestimates actual adherence compared to objective measures that minimize opportunities for participant manipulation which include electronic devices for medication monitoring, unannounced pill or products count, pharmacy refills, and biomarkers of gel applicator insertion) [46]. While useful, drug levels are costly, not always practical in routine clinical practice and they do not inform patterns of adherence. Therefore, in absence of a gold standard, combining more than one objective measures of adherence is likely to provide the best estimate of true adherence.

There are limited intervention studies aimed at improving ART adherence in the context of PrEP or TasP to guide evidence-based recommendations. Selected ART adherence interventions that have proven effective in ART-naïve or experienced population could be of value and include use of electronic reminders using mobile phones or other devices [47,48], screening for and treating depression [49], addressing substance abuse [50], organizing pillboxes [51], social support [52] and simplifying ART regimens by reducing pill burden and frequency (e.g. once-daily single tablet regimen) [53] as well as one-to-one counseling [54,55]. It will be critical to start to collect specific ART adherence data in the context of PrEP and/or TasP and evaluate evaluation of the above interventions or other novel high impact interventions [55].

As an example, the Pay-for-Performance-for-Patients (P4P4P) initiative is a controversial contingency management with monetary incentive, in the context of overcoming barriers to HIV testing and care and improving prevention and treatment outcomes for people with and at risk for HIV infection. The P4P4P approach has been shown to be effective for smoking cessation [56] and weight loss [57], improving adherence to chronic medication in substance abuse patients [58], hepatitis [59], latent tuberculosis infection [60] and HIV infection $[61,62]$ using cash or cash-like incentives. This approach also showed significantly improved adherence during the study period, but had no appreciable lasting effect on medication-taking behavior after the incentives were withdrawn. However, most of all these studies were small and raised more questions about generalizability, feasibility, sustainability in real-life setting, ethical concerns and cost-effectiveness, therefore calling for further research. More recently, the Test and Link to Care (TLC)-Plus - the HPTN 065 study in US (Washington DC and New York City: intervention community; vs. Chicago, Miami, Philadelphia and Houston) is evaluating the feasibility of an enhanced community level HIV testing, link-to-care and treat strategy and whether patient incentives are effective for linkage in care; specifically, does a monetary voucher work better than just a referral. In addition, it is investigating the effectiveness of financial incentives in promoting virologic suppression, with patients being rewarded contingent upon the results of their viral load tests. Participants receive $\$ 25$ for being tested for HIV, $\$ 70$ for enrollment in care and $\$ 280$ per year for nondetectable viral load. Interestingly, data from developing countries by Baird and colleagues showed that structural interventions that do not directly target sexual behavior change could be important components of HIV prevention strategies. In a cluster-randomized trial, cash transfer programmes reduced HIV and HSV-2 infections in adolescent schoolgirls in Malawi [63].

Finally, non-financial incentives, such as mobile phone airtime, food vouchers, may be useful way to improve ART adherence and retention in care and on-going studies are on-going to evaluate such interventions or other new ones [55].

\section{Conclusion}

New successes in HIV prevention research (PrEP, TasP, PMTCT etc.) have been tempered by suboptimal adherence. There is a critical need to define practical and effective adherence monitoring strategies as well as controlled trials of adherence interventions in the era of PrEP, TasP, and PMTCT to maximize their benefit. Health care providers should ensure that ART doses fit into patients' daily routines, probable side effects should be explained and how to hand these when they occur. Finally, cost analysis and cost-effectiveness data of interventions to maximize outcomes of prevention strategies would be helpful to guide policy-makers as ART program are being expanded globally.

\section{Acknowledgments}

Dr Nachega acknowledge support from the US NIH-FIC/HRSA PEPFAR Grant Award, T84HA21652-01-00 for Medical Education Partnership Initiative (MEPI) (JBN); The European Developing Countries Clinical Trial Partnership (EDCTP) Senior Fellowship Award: TA-08-40200- 021 (JBN); and The Wellcome Trus Southern Africa Consortium for Research Excellence (SACORE): WT087537MA.

\section{References}

1. UNAIDS World AIDS day report (2011) How to get to zero: faster, smarter, better The Joint United Nations Programme on HIVIAIDS, Geneva, Switzerland.

2. WHO Global HIVIAIDS response (2011) Epidemic update and health sector progress towards universal access. Progress report 2011, World Health Organization, Geneva, Switzerland.

3. Holmes KK, Levine R, Weaver M (2004) Effectiveness of condoms in preventing sexually transmitted infections. Bull World Health Organ 82: 454-461.

4. Hughes J, Baeten J, Lingappa J, Magaret A, Wald A, et al. (2011) Determinants of Per-act Infectivity of HIV-1 in the Partners in Prevention Study. 18th Conference on Retroviruses and Opportunistic Infections, Boston, MA, USA. 
Citation: Nachega JB, Uthman OA, Mills EJ, Quinn TC (2012) Adherence to Antiretroviral Therapy for the Success of Emerging Interventions to Prevent HIV Transmission: A Wake up Call. J AIDS Clinic Res S4:007. doi:10.4172/2155-6113.S4-007

Page 5 of 6

5. UNAIDS (2009) Condoms and HIV prevention: Position statement by UNAIDS, UNFPA and WHO. Geneva, Switzerland.

6. Weller S, Davis K (2002) Condom effectiveness in reducing heterosexual HIV transmission. Cochrane database syst Rev CD003255.

7. Kwon JA, Iversen J, Maher L, Law MG, Wilson DP (2009) The impact of needle and syringe programs on HIV and HCV transmissions in injecting drug users in Australia: a model-based analysis. J Acquir Immune Defic Syndr 51: 462-469.

8. Auvert B, Taljaard D, Lagarde E, Sobngwi-Tambekou J, Sitta R,et al. (2005) Randomized, controlled intervention trial of male circumcision for reduction of HIV infection risk: the ANRS 1265 Trial. PLoS medicine 2: e298.

9. Bailey RC, Moses S, Parker CB, Agot K, Maclean I, et al. (2007) Male circumcision for HIV prevention in young men in Kisumu, Kenya: a randomised controlled trial. Lancet 369: 643-656.

10. Gray RH, Kigozi G, Serwadda D, Makumbi F, Watya S, et al. (2007) Male circumcision for HIV prevention in men in Rakai, Uganda: a randomised trial. Lancet 369: 657-666.

11. Cohen MS, Chen YQ, McCauley M, Gamble T, Hosseinipour MC, et al. (2011) Prevention of HIV-1 infection with early antiretroviral therapy. N Engl J Med 365: 493-505.

12. Das M, Chu PL, Santos GM, Scheer S, Vittinghoff E, et al. (2010) Decreases in community viral load are accompanied by reductions in new HIV infections in San Francisco. PLoS One 5: e11068.

13. Montaner JS, Lima VD, Barrios R, Yip B, Wood E, et al. (2010) Association of highly active antiretroviral therapy coverage, population viral load, and yearly new HIV diagnoses in British Columbia, Canada: a population-based study. Lancet 376: 532-539.

14. Nachega JB, Hislop M, Dowdy DW, Chaisson RE, Regensberg L, et al. (2007) Adherence to nonnucleoside reverse transcriptase inhibitor-based HIV therapy and virologic outcomes. Ann Intern Med 146: 564-573.

15. Paterson DL, Swindells S, Mohr J, Brester M, Vergis EN, et al. (2000) Adherence to protease inhibitor therapy and outcomes in patients with HIV infection. Annals of internal medicine 133: 21-30.

16. Wood E, Hogg RS, Yip B, Harrigan PR, O'Shaughnessy MV, et al. (2004) The impact of adherence on CD4 cell count responses among HIV-infected patients. J Acquir Immune Defic Syndr 35: 261-268.

17. Nachega JB, Hislop M, Dowdy DW, Lo M, Omer SB, et al. (2006) Adherence to highly active antiretroviral therapy assessed by pharmacy claims predicts survival in HIV-infected South African adults. J Acquir Immune Defic Syndr 43: 78-84.

18. Wood E, Hogg RS, Yip B, Moore D, Harrigan PR, et al. (2006) Impact of baseline viral load and adherence on survival of HIV-infected adults with baseline CD4 cell counts $>$ or $=200$ cells/microl. AIDS 20: 1117-1123.

19. Grosskurth H, Gray R, Hayes R, Mabey D, Wawer M (2000) Control of sexually transmitted diseases for HIV-1 prevention: understanding the implications of the Mwanza and Rakai trials. Lancet 355: 1981-1987.

20. Grosskurth H, Mosha F, Todd J, Mwijarubi E, Klokke A, Senkoro et al. (1995) Impact of improved treatment of sexually transmitted diseases on HIV infection in rural Tanzania: randomised controlled trial. Lancet 346: 530-536.

21. Wawer MJ, Sewankambo NK, Serwadda D, Quinn TC, Paxton LA, et al. (1999) Control of sexually transmitted diseases for AIDS prevention in Uganda: a randomised community trial. Rakai Project Study Group. Lancet 353: 525-535.

22. Celum C, Wald A, Hughes J, Sanchez J, Reid S, et al. (2008) Effect of aciclovir on HIV-1 acquisition in herpes simplex virus 2 seropositive women and men who have sex with men: a randomised, double-blind, placebo-controlled trial. Lancet 371: 2109-2119.

23. Grant RM, Hamer D, Hope T, Johnston R, Lange J, et al. (2008) Whither or wither microbicides? Science 321: 532-534.

24. Van Damme L, Govinden R, Mirembe FM, Guedou F, Solomon S, et al. (2008) Lack of effectiveness of cellulose sulfate gel for the prevention of vaginal HIV transmission. N Engl J Med 359: 463-472.

25. Van Damme L, Ramjee G, Alary M, Vuylsteke B, Chandeying V, et al. (2002) Effectiveness of COL-1492, a nonoxynol-9 vaginal gel, on HIV-1 transmission in female sex workers: a randomised controlled trial. Lancet 360: 971-977.

26. Gallo MF, Kilbourne-Brook M, Coffey PS (2012) A review of the effectiveness and acceptability of the female condom for dual protection. Sex health 9 : 18-26.

27. Johnston MI, Fauci AS (2011) HIV vaccine development--improving on natural immunity. N Engl J Med 365: 873-875.

28. Nabel GJ, Kwong PD, Mascola JR (2011) Progress in the rational design of an AIDS vaccine. Philos Trans R Soc Lond B Biol Sci 366: 2759-2765.

29. De Cock KM, Fowler MG, Mercier E, de Vincenzi I, Saba J, et al. (2000) Prevention of mother-to-child HIV transmission in resource-poor countries: translating research into policy and practice. JAMA 283: 1175-1182.

30. Townsend CL, Cortina-Borja M, Peckham CS, de Ruiter A, Lyall H, et al. (2008) Low rates of mother-to-child transmission of HIV following effective pregnancy interventions in the United Kingdom and Ireland, 2000-2006. AIDS 22: 973-981.

31. Quinn TC, Wawer MJ, Sewankambo N, Serwadda D, Li C, et al. (2000) Vira load and heterosexual transmission of human immunodeficiency virus type 1. Rakai Project Study Group. N Engl J Med 342: 921-929.

32. Anglemyer A, Rutherford GW, Baggaley RC, Egger M, Siegfried N (2011) Antiretroviral therapy for prevention of HIV transmission in HIV-discordant couples. Cochrane Database Syst Rev CD009153.

33. Abdool Karim Q, Abdool Karim SS, Frohlich JA, Grobler AC, Baxter C, et al (2010) Effectiveness and safety of tenofovir gel, an antiretroviral microbicide for the prevention of HIV infection in women. Science 329: 1168-1174.

34. Grant RM, Lama JR, Anderson PL, McMahan V, Liu AY, et al. (2010) Preexposure chemoprophylaxis for HIV prevention in men who have sex with men. N Engl J Med 363: 2587-2599.

35. Van Damme L, Corneli A, Ahmed K, Agot K, Lombaard J, et al. (2012) Preexposure Prophylaxis for HIV Infection among African Women. N Engl J Med 367: 411-422.

36. MTN Statement on Decision to Discontinue Use of Tenofovir Gel in VOICE, a Major HIV Prevention Study in Women. Pittsburgh.

37. Thigpen MC, Kebaabetswe PM, Paxton LA, Smith DK, Rose CE, et al. (2012) Antiretroviral Preexposure Prophylaxis for Heterosexual HIV Transmission in Botswana. N Engl J Med 367: 423-434.

38. Baeten JM, Donnell D, Ndase P, Mugo NR, Campbell JD, et al. (2012) Antiretroviral Prophylaxis for HIV Prevention in Heterosexual Men and Women. N Engl J Med 367: 399-410.

39. Haberer JE, Baeten J, Celum C, Tumwesigye E, Katabira E, et al. (2011) Near perfect early adherence to antiretroviral PrEP against HIV infection among HIV serodiscordant couples as determined by multiple measures: preliminary data from the partners PrEP study. 18th Conference on Retroviruses and Opportunistic Infections. Boston, Massachusetts.

40. Ware NC, Wyatt MA, Haberer JE, Baeten JM, Kintu A, et al. (2012) What's love got to do with it? Explaining adherence to oral antiretroviral pre-exposure prophylaxis for HIV-serodiscordant couples. J Acquir Immune Defic Syndr 59 : 463-468.

41. van der Straten A, Van Damme L, Haberer JE, Bangsberg DR (2012) Unraveling the divergent results of pre-exposure prophylaxis trials for HIV prevention. AIDS 26: F13-19.

42. Donnell D, Baeten JM, Kiarie J, Thomas KK, Stevens W, et al. (2010) Heterosexual HIV-1 transmission after initiation of antiretroviral therapy: a prospective cohort analysis. Lancet 375: 2092-2098.

43. Granich RM, Gilks CF, Dye C, De Cock KM, Williams BG (2009) Universa voluntary HIV testing with immediate antiretroviral therapy as a strategy for elimination of HIV transmission: a mathematical model. Lancet 373: 48-57.

44. Mills EJ, Nachega JB, Buchan I, Orbinski J, Attaran A, et al. (2006) Adherence to antiretroviral therapy in sub-Saharan Africa and North America: a metaanalysis. JAMA 296: 679-690.

45. Hall HI, Hughes D, Dean HD, Mermin JH, Fenton KA, et al. (2011) HIV Infection - United States, 2005 and 2008. MMWR Surveill Summ 60: 87-89.

46. Rudd P, Byyny RL, Zachary V, LoVerde ME, Titus C, et al. (1989) The natura history of medication compliance in a drug trial: limitations of pill counts. Clin pharmacol Ther 46: 169-176.

47. Lester RT, Ritvo P, Mills EJ, Kariri A, Karanja S, Chung MH, et al. (2010) Effects of a mobile phone short message service on antiretroviral treatment adherence in Kenya (WelTel Kenya1): a randomised trial. Lancet 376: 1838-1845. 
Citation: Nachega JB, Uthman OA, Mills EJ, Quinn TC (2012) Adherence to Antiretroviral Therapy for the Success of Emerging Interventions to Prevent HIV Transmission: A Wake up Call. J AIDS Clinic Res S4:007. doi:10.4172/2155-6113.S4-007

Page 6 of 6

48. Pop-Eleches $C$, Thirumurthy $H$, Habyarimana JP, Zivin JG, Goldstein MP, et al. (2011) Mobile phone technologies improve adherence to antiretroviral treatment in a resource-limited setting: a randomized controlled trial of text message reminders. AIDS 25: 825-834.

49. Safren SA, O'Cleirigh C, Tan JY, Raminani SR, Reilly LC, Otto MW, et al. (2009) A randomized controlled trial of cognitive behavioral therapy for adherence and depression (CBT-AD) in HIV-infected individuals. Health Psychol 28: 1-10.

50. Altice FL, Bruce RD, Lucas GM, Lum PJ, Korthuis PT, et al. (2011) HIV treatment outcomes among HIV-infected, opioid-dependent patients receiving buprenorphine/naloxone treatment within HIV clinical care settings: results from a multisite study. J Acquir Immune Defic Syndr 56: S22-S32.

51. Petersen ML, Wang Y, van der Laan MJ, Guzman D, Riley E, Bangsberg DR (2007) Pillbox organizers are associated with improved adherence to HIV antiretroviral therapy and viral suppression: a marginal structural model analysis. Clin Infect Dis 45: 908-915.

52. Uchino BN (2006) Social support and health: a review of physiological processes potentially underlying links to disease outcomes. J Behav Med 29: 377-387.

53. Nachega JB, Mugavero MJ, Zeier M, Vitoria M, Gallant JE (2011) Treatment simplification in HIV-infected adults as a strategy to prevent toxicity, improve adherence, quality of life and decrease healthcare costs. Patient Prefer Adherence 5: 357-367.

54. Chung MH, Richardson BA, Tapia K, Benki-Nugent S, Kiarie JN, et al. (2011) $A$ randomized controlled trial comparing the effects of counseling and alarm device on HAART adherence and virologic outcomes. PLoS Med 8: e1000422.

55. Thompson MA, Mugavero MJ, Amico KR, Cargill VA, Chang LW, et al. (2012) Guidelines for Improving Entry Into and Retention in Care and Antiretroviral
Adherence for Persons With HIV: Evidence-Based Recommendations From an International Association of Physicians in AIDS Care Panel. Ann Intern Med 156: 817-833.

56. Volpp KG, Troxel AB, Pauly MV, Glick HA, Puig A, et al. (2009) A randomized, controlled trial of financial incentives for smoking cessation. N Engl J Med 360: 699-709.

57. Volpp KG, John LK, Troxel AB, Norton L, Fassbender J, et al. (2008) Financia incentive-based approaches for weight loss: a randomized trial. JAMA 300 2631-2637.

58. Stitzer ML, Polk T, Bowles S, Kosten T (2010) Drug users' adherence to a 6-month vaccination protocol: effects of motivational incentives. Drug Alcohol Depend 107: 76-79.

59. Seal KH, Kral AH, Lorvick J, McNees A, Gee L, et al. (2003) A randomized controlled trial of monetary incentives vs. outreach to enhance adherence to the hepatitis $B$ vaccine series among injection drug users. Drug Alcohol Depend 71: 127-131.

60. Malotte CK, Hollingshead JR, Larro M (2001) Incentives vs outreach workers for latent tuberculosis treatment in drug users. Am j prev med 20: 103-107.

61. Haug NA, Sorensen JL (2006) Contingency management interventions for HIVrelated behaviors. Current HIVIAIDS Rep 3: 154-159.

62. Rosen MI, Dieckhaus K, McMahon TJ, Valdes B, Petry NM, et al. (2007) Improved adherence with contingency management. AIDS patient care and STDS 21: 30-40.

63. Baird SJ, Garfein RS, Mclntosh CT, Ozler B (2012) Effect of a cash transfer programme for schooling on prevalence of HIV and herpes simplex type 2 in Malawi: a cluster randomised trial. Lancet 379: 1320-1329.
This article was originally published in a special issue, Epidemiology and Prevention: HIV handled by Editor(s). Dr. Han-zhu Qian, Vanderbilt University School of Medicine, USA 